\title{
Electrochemical, Quantum Calculations and Monte Carlo Simulation Studies of N1,N2-Bis(1-Phenylethylidene) Ethane-1,2-Diamine as a Corrosion Inhibitor for Carbon Steel in a 1.0 M Hydrochloric Acid Solution
}

\author{
Fadoua El Hajjaji ${ }^{a}$, Mohammed E. Belghiti ${ }^{b}$, Meriem Drissi ${ }^{c}$, \\ Mohammed Fahim ${ }^{c}$, Rajae Salim ${ }^{a, d}$, Belkheir Hammouti ${ }^{b}$, \\ Mustapha Taleb ${ }^{a}$ and Ayssar Nahlée,* \\ ${ }^{a}$ Laboratory of Engineering, Electrochemistry, Modeling and Environment (LIEME), \\ Faculty of Sciences, University Sidi Mohamed Ben Abdellah, Fez, Morocco \\ ${ }^{b}$ Laboratory of Applied Analytical Chemistry Materials and Environment (LCAAE), \\ Faculty of Sciences, University of Mohammed Premier, Oujda, Morocco \\ ${ }^{c}$ Laboratory of Materials Chemistry and Bio-technology of Naturals Products, \\ Faculty of Sciences, University Moulay Ismail, Meknes, Morocco \\ ${ }^{d}$ Laboratory of Separation Processes, Faculty of Sciences, \\ University Ibn-Tofail, Kenitra, Morocco \\ ${ }^{e}$ Department of Chemistry, College of Sciences, University of Sharjah, \\ Sharjah, P.O. Box 27272, United Arab Emirates
}

Received June 23, 2017; accepted December 20, 2017

\begin{abstract}
N1,N2-Bis(1-Phenylethylidene)ethane-1,2-diamine (PEED) was tested as a corrosion inhibitor for $\mathrm{C}$-steel in a $1.0 \mathrm{M} \mathrm{HCl}$ solution, by using potentiodynamic polarization and electrochemical impedance spectroscopy (EIS) techniques. The results showed that PEED is a very good inhibitor, as its inhibition efficiency reached $93.8 \%$, with a concentration of $1.0 \times 10^{-3} \mathrm{M}$, at $298 \mathrm{~K}$. Tafel polarization study revealed that PEED acted as a mixed type inhibitor that obeyed Langmuir adsorption isotherm. The thermodynamic activation parameters for the corrosion reaction were calculated and discussed. Quantum chemical parameters and Fukui function were obtained by $\mathrm{DMol}^{3} / \mathrm{GGA} / \mathrm{PW} 91 / \mathrm{DNP}+$ level of theory, which was performed using Materials Studiov 8.0 software from Biovia-Accelrys. Monte Carlo simulation was implemented to search for the equilibrium configurations of the PEED/Fe(111) adsorption system, in a $1.0 \mathrm{M}$ hydrochloric acid solution.
\end{abstract}

Keywords: corrosion, inhibitor, N1,N2-Bis(1-Phenylethylidene)ethane-1,2-diamine, Langmuir adsorption isotherm, quantum chemical parameters and Monte Carlo simulation.

\footnotetext{
* Corresponding author. E-mail address: anahle@sharjah.ac.ae
} 


\section{Introduction}

Carbon steel (C-steel) is among the most widely used materials in many industrial fields, such as metal processing equipment, marine applications, nuclear power plants, fossil fuel plants and construction. Acidic solutions, especially hydrochloric acid $(\mathrm{HCl})$, are often used in many industrial processes, including acid pickling, chemical cleaning, elimination of localized deposits, and removal of undesirable scale in metals working. However, materials could be corroded during these applications, resulting in waste of resources [1].

For reducing materials' corrosion rate, many methods have been used, but inhibitors remain one of the most practical techniques for corrosion protection in acidic media [2], especially organic compounds containing heteroatoms, such as nitrogen (-N-), oxygen (-O-), and sulfur (-S-) [3], and also compounds with multiple bonds $(\pi-\pi)$, as they adsorb onto the C-steel surface [4-6].

The aim of this study is to investigate the inhibition effect of N1,N2-bis(1phenylethylidene)ethane-1,2-diamine (PEED) on C-steel corrosion, in a $1.0 \mathrm{M}$ $\mathrm{HCl}$ solution, using electrochemical measurements. Every quantum chemical parameter was obtained by DMol3/GGA/PW91/DNP+ level of theory in an isolated form, which helped to understand PEED adsorption properties. PEED's molecular structure is shown in Scheme 1.

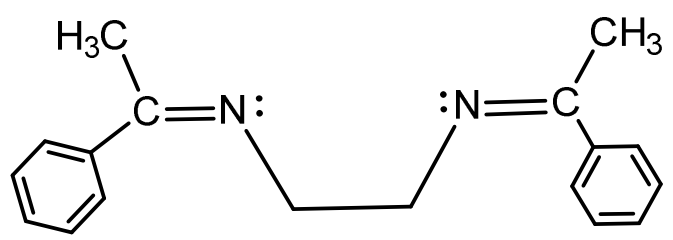

Scheme 1. Molecular structure of PEED.

\section{Experimental work}

\section{Synthesis of N1,N2-bis(1-phenylethylidene)ethane-1,2-diamine}

N1,N2-Bis(1-Phenylethylidene)ethane-1,2-diamine (PEED) was prepared by condensation under reflux in ethanol, with two equivalents of acetophenone, and ethylenediamine (Reaction 1). The reaction mixture was heated at reflux for 4 hours. The solvent was evaporated under vacuum, and then cooled to $0{ }^{\circ} \mathrm{C}$. The yellow solid was collected and washed with hexane and ether, with a percentage yield $=60 \%$. Table 1 shows some physical properties of the reactants and of the product.

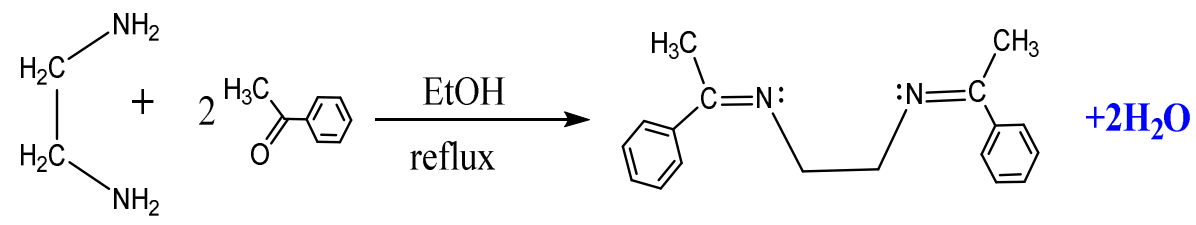

Reaction 1. 


\section{IR spectroscopy of PEED}

IR spectroscopy of the N1,N2-BIS(1-phenyl ethylidene)ethane-1,2-diamine ligand (PEED) showed, by comparison with the infrared spectrum of ethylenediamine and acetophenone, the disappearance of ketone's bands of vibration of $v_{\mathrm{C}=\mathrm{O}}$, located to $1750 \mathrm{~cm}^{-1}$, and of $v_{\mathrm{NH} 2}$, at $3300 \mathrm{~cm}^{-1}$, characteristic of a primary amine.

Table 1. Physical properties of the reactants and of the product.

\begin{tabular}{|c|c|c|c|c|c|}
\hline Product & Formula & $\begin{array}{c}\text { Molecular } \\
\text { weight } / \mathbf{g . m o l} \mathbf{- 1}^{-1}\end{array}$ & $\begin{array}{c}\text { Melting } \\
\text { point } /{ }^{\circ} \mathbf{C}\end{array}$ & Solubility & $\begin{array}{c}\text { Percentage } \\
\text { yield/ \% }\end{array}$ \\
\hline Acetophenone & $\mathrm{C}_{8} \mathrm{H}_{8} \mathrm{O}$ & 120.1 & viscous liquid & - & - \\
\hline Ethylenediamine & $\mathrm{C}_{2} \mathrm{H}_{8} \mathrm{~N}_{2}$ & 60.2 & liquid & - & - \\
\hline PEED & $\mathrm{C}_{18} \mathrm{H}_{20} \mathrm{~N}_{2}$ & 264 & 118 & $\begin{array}{c}\text { Ethanol } \\
\text { and DMSO }\end{array}$ & 60 \\
\hline
\end{tabular}

The IR spectroscopy also showed the appearance of a new band at $1620 \mathrm{~cm}^{-1}$, corresponding to the vibration of $v_{\mathrm{C}=\mathrm{N}}$ [7], and another band at $1510 \mathrm{~cm}^{-1}$, corresponding to the vibration of $v_{\mathrm{C}=\mathrm{C}}$, as illustrated in Table 2 .

Table 2. IR Characteristics of N1,N2-BIS(1-phenyl ethylidene)ethane-1,2-diamine (PEED).

\begin{tabular}{|c|c|}
\hline v in cm $^{-1}$ & Attribution \\
\hline $\mathbf{3 1 0 0}$ & $v\left(\mathrm{CH}_{\text {aromatic }}\right)(\mathrm{sp} 2)$ \\
\hline $\mathbf{1 5 1 0}$ & $v\left(\mathrm{C}=\mathrm{C}_{\text {aromatic }}\right)$ \\
\hline $\mathbf{1 6 2 0}$ & $v(\mathrm{C}=\mathrm{N})$ \\
\hline $\mathbf{2 8 0 0 - 2 9 0 0}$ & $v\left(\mathrm{CH}_{\mathrm{sp} 3}\right)$ \\
\hline
\end{tabular}

\section{Material preparation}

The chemical composition of the C-steel used in this work is shown in Table 3. The sample surface was prepared by polishing with emery paper at various grades ranging from 100 to 1200, rinsing with distilled water, degreasing in acetone, and drying in hot air. The $\mathrm{C}$-steel specimens had a rectangular shape. A $1.0 \mathrm{M} \mathrm{HCl}$ solution was prepared by dilution of analytical grade $\mathrm{HCl}(37 \% \mathrm{w} / \mathrm{w})$ with distilled water.

Table 3. Chemical composition of C-steel.

\begin{tabular}{|c|c|c|c|c|c|c|c|}
\cline { 2 - 8 } \multicolumn{1}{c|}{} & \multicolumn{7}{c|}{ C-Steel composition, (weight \%) } \\
\hline Element & Fe & Si & C & Mn & S & P & Al \\
\hline \% weight & 99.21 & 0.38 & 0.21 & 0.05 & 0.05 & 0.09 & 0.01 \\
\hline
\end{tabular}

\section{Polarization measurements}

Electrochemical experiments were carried out using a potentiostat (Voltalab-PGZ 301), coupled to a computer equipped with Voltamaster 4 software. The working electrode consisted of a $1.0 \mathrm{~cm}^{2} \mathrm{C} 38$ steel disk. Prior to each experiment, the electrode was polished using emery papers ranging from 100 to 1200 grades. After that, the electrode was ultrasonically cleaned with distillate water. A saturated calomel electrode (SCE) was used as reference electrode. The counter 
electrode was a platinum plate with a large surface area. In addition, the working electrode was immersed in the test solution for $30 \mathrm{~min}$, until a steady state open circuit potential was reached. Tafel polarization curves were recorded by scanning the electrode potential from - $900 \mathrm{mV}$ to $-100 \mathrm{mV}$, under potentiodynamic conditions corresponding to $1.0 \mathrm{mV} / \mathrm{s}$, and under air atmosphere.

\section{Impedance spectroscopy measurement}

Electrochemical impedance spectroscopy (EIS) is an efficient method for corrosion studies of metallic materials. It was carried out using a transfer function analyzer (VoltaLab PGZ 100), with a small amplitude a.c. signal (10 $\mathrm{mV}$ ), over a frequency domain of $100 \mathrm{kHz}$ to $10 \mathrm{mHz}$. The EIS diagrams have been illustrated in the Nyquist representation. The results were then analyzed in equivalence terms.

\section{Quantum chemical calculations}

The quantum chemical calculations were carried out to elucidate the correlation between the inhibitor molecular structure and its efficiency. Quantum chemical calculations were performed using the $\mathrm{DMol}^{3}$ module implemented in material studio v8.0, distributed by BIOVIA (formerly Accelrys) [8]. The geometry of the studied compound was evaluated using GGA/PW91 level and DNP+ basis set for all atoms [9-13]. Theoretical parameters, such as energy of the highest occupied molecular orbital ( $\left.\mathrm{E}_{\text {HOMO }}\right)$, energy of the lowest unoccupied molecular orbital ( $\left.\mathrm{E}_{\mathrm{LUMO}}\right)$, energy gap $\left(\Delta \mathrm{E}_{\mathrm{g}}=\mathrm{E}_{\mathrm{HOMO}}-\mathrm{E}_{\mathrm{LUMO}}\right)$, dipole moment $(\mu)$, electron affinity $\left(\mathrm{A}=-\mathrm{E}_{\mathrm{LUMO}}\right)$, ionization potential $\left(\mathrm{I}=-\mathrm{E}_{\mathrm{HOMO}}\right)$, and number of transferred electrons $(\Delta \mathrm{N})$ were calculated.

The absolute electronegativity $(\chi)$ is the measure of the ability of an atom or group of atoms to attract electrons to them [14], and can be approached as the following equations [15]:

$$
\begin{aligned}
& \chi=1 / 2(\mathrm{I}+\mathrm{A}) \\
& \eta=1 / 2(\mathrm{I}-\mathrm{A}) \\
& \sigma=\frac{1}{\eta}
\end{aligned}
$$

where $\chi$ is the absolute electronegativity, $\eta$ is the hardness, and $\sigma$ is the softness. The dipole moment $(\mu)$ is another index that is often used for the prediction of the direction of a corrosion inhibition process. It is a polarity measure in a bond, and is related to the electrons distribution in a molecule [16]. The fraction of electrons transferred from the inhibitor to the metallic surface $(\Delta N)$ was estimated according to Pearson theory [17], by using the following equation:

$$
\Delta N=\frac{\chi_{F e}-\chi_{i n h}}{2\left(\eta_{F e}-\eta_{i n h}\right)}
$$


where $\Delta \mathrm{N}$ is the fraction of transferred electrons, $\chi_{\mathrm{Fe}}$ and $\chi_{\mathrm{inh}}$ are iron absolute electronegativity and the inhibitor molecule, and $\eta_{\mathrm{Fe}}$ and $\eta_{\text {inh }}$ are iron absolute hardness and the inhibitor molecule, respectively. The theoretical value for iron electronegativity was $\chi_{\mathrm{Fe}}=7 \mathrm{eV}$, and a global hardness of $\eta_{\mathrm{Fe}}=0 \mathrm{eV}$ [18].

\section{Monte Carlo simulations}

The Monte Carlo (MC) simulation was used to calculate the low-configuration adsorption energy of the interactions between the single inhibitor molecule (PEED) and the clean iron surface in a $1.0 \mathrm{M} \mathrm{HCl}$ solution. The Metropolis Monte Carlo [19] methodology, with the adsorption locator module [20], implemented in the Materials Studio (Accelrys) [8] package, was used to build a system (iron substrate / inhibitor / solvent molecules). The simulations were carried out with a slab thickness of $5 \AA$, a supercell of $6 \times 6$, and a vacuum of 30 $\AA$ along the $\mathrm{C}$ axis in a simulation box, $(25.17 \times 25.37 \times 40.26) \AA^{3}$ with periodic boundary conditions to model the representative part of the interface devoid of any arbitrary boundary effect. For the entire simulation procedure, COMPASS force field [21] was used to optimize the structures of all the corrosion system components (PEED / Fe (111) / $110 \mathrm{H}_{2} \mathrm{O} / 2 \mathrm{HCl}$ ). To mimic the actual corrosion environment, the effect of ions such as $\left(\mathrm{H}_{3} \mathrm{O}^{+}\right)$and $\left(\mathrm{Cl}^{-}\right)$was also taken into account during the simulation [22-23]. This calculation study aimed to find low energy adsorption active sites to study the preferential adsorption of inhibitory molecules onto the iron surface in an acidic medium, in order to find a relationship between the effect of the inhibitor's molecular structure and its inhibition efficiency [23].

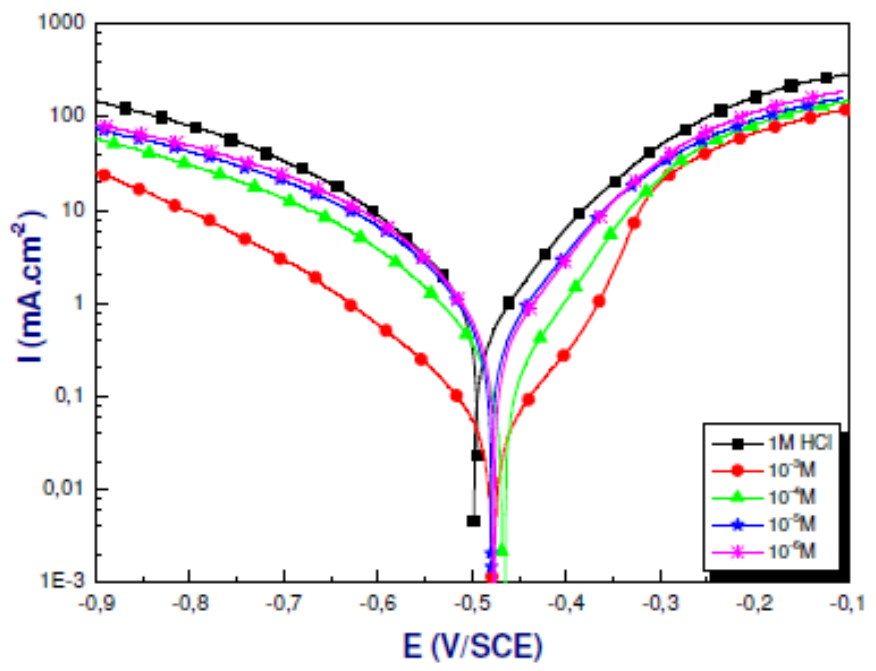

Figure 1. Polarization curves of $\mathrm{C}$-steel in a $1.0 \mathrm{M} \mathrm{HCl}$ solution for various PEED concentrations. 


\section{Results and discussion}

\section{Effect of concentration}

Potentiodynamic polarization measurements

Fig. 1 shows the polarization curves of $\mathrm{C}$-steel in a $1.0 \mathrm{M} \mathrm{HCl}$ solution, in the absence and presence of various inhibitor concentrations. The inhibition efficiency for each concentration was calculated using Equation 5. The electrochemical parameters, such as $I_{c o r r}, E_{c o r r}$, Tafel slopes $(\beta c$ and $\beta a)$ and percentage inhibition efficiency (IE \%), were calculated using the following equation:

$$
I E \%=\frac{I_{\text {corr }}-I_{\text {corr }}^{\prime}}{I_{\text {corr }}}
$$

where $\mathrm{I}_{\text {corr }}$ and I' corr are the corrosion current densities without and with various inhibitor concentrations, respectively.

The corrosion current densities were determined by the extrapolation of the Tafel slopes in Table 4, where it can be seen that the current density decreases in the inhibitor presence.

Table 4. Potentiodynamic electrochemical parameters for C-steel corrosion in a $1.0 \mathrm{M}$ $\mathrm{HCl}$ solution, in the inhibitor absence and presence.

\begin{tabular}{|l|c|c|c|c|c|}
\hline \multicolumn{1}{|c|}{ System } & $\begin{array}{c}\mathbf{E}_{\text {corr }} \\
(\mathbf{m V} \text { vs. SCE })\end{array}$ & $\begin{array}{c}\mathbf{I}_{\text {corr }} \\
\left(\boldsymbol{\mu} \mathbf{A . c m}^{-2}\right)\end{array}$ & $\begin{array}{c}\mathbf{B}_{\mathbf{c}} \\
\left(\mathbf{m V . d e c}^{-1}\right)\end{array}$ & $\begin{array}{c}\mathbf{B}_{\mathbf{a}} \\
\left(\mathbf{m V . d e c}^{-1}\right)\end{array}$ & IE\% \\
\hline $1.0 \mathrm{M} \mathrm{HCl}$ solution & -452 & 485 & -85 & 77 & - \\
\hline $1.0 \mathrm{M} \mathrm{HCl}+1.0 \times 10^{-3} \mathrm{M}$ PEED & -476 & 30 & -89 & 74 & 93.8 \\
\hline $1.0 \mathrm{M} \mathrm{HCl}+1.0 \times 10^{-4} \mathrm{M}$ PEED & -465 & 159 & -76 & 64 & 67.2 \\
\hline $1.0 \mathrm{M} \mathrm{HCl}+1.0 \times 10^{-5} \mathrm{M}$ PEED & -475 & 375 & -80 & 65 & 22.7 \\
\hline $1.0 \mathrm{M} \mathrm{HCl}+1.0 \times 10^{-6} \mathrm{M}$ PEED & -473 & 379 & -77 & 68 & 21.8 \\
\hline
\end{tabular}

Therefore, the inhibitory efficiency increases with higher additive concentrations, reaching a maximum value of $93.8 \%$, at $1.0 \times 10^{-3} \mathrm{M}$ (Fig. 2).

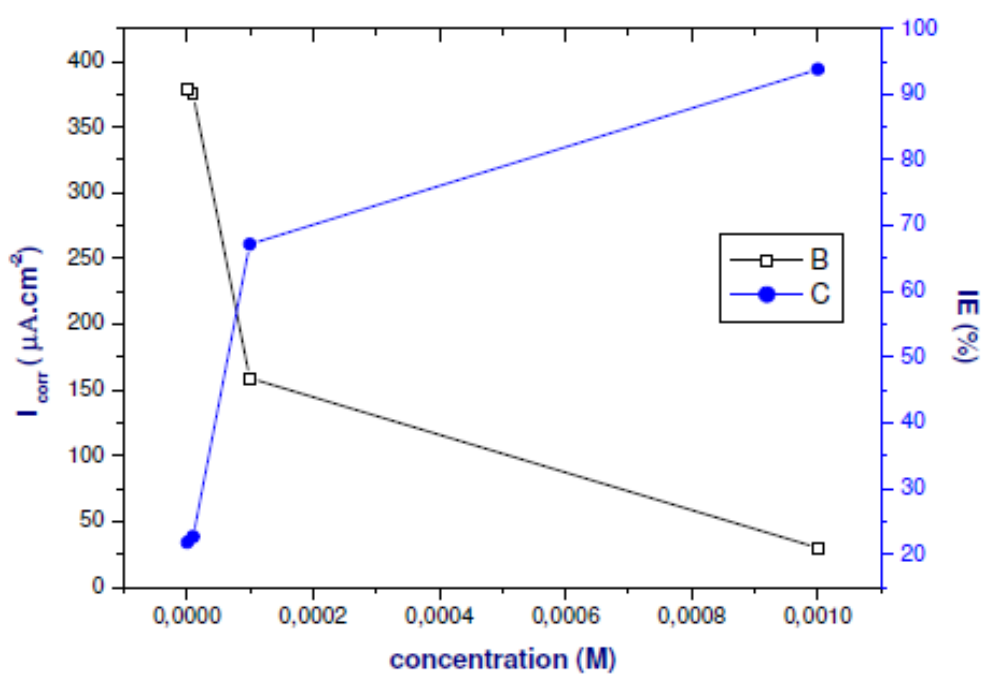

Figure 2. Variation of corrosion rate and inhibition efficiency with the inhibitor concentration. 
Literally, when the displacement in the potential is greater than $85 \mathrm{mV} / \mathrm{E}_{\text {corr, }}$, the inhibitor may be considered as of the anodic or cathodic type; it will be considered as mixed, if the displacement in the potential is less than $85 \mathrm{mV} / \mathrm{E}_{\text {corr }}$ [24]. In our case, the maximum displacement is less than $85 \mathrm{mV} / \mathrm{E}_{\text {corr, }}$ suggesting that PEED acted as a mixed inhibitor. Fig. 1 shows that the potential value of $1.0 \times 10^{-3} \mathrm{M}$ is greater than $-350 \mathrm{mV}$ vs. SCE. The PEED compound begins to be desorbed, reflecting the formation of anodic protective films containing oxides, which explains the obtained inhibition efficiency [25].

Electrochemical impedance spectroscopy (EIS)

C-steel corrosion behavior in an acidic solution, in the presence of our compound, was studied by EIS at $298 \mathrm{~K}$, after 30 minutes of immersion at the corrosion potential. Nyquist C-steel plots, in uninhibited and inhibited acid solutions containing different PEED concentrations, are shown in Fig. 3.

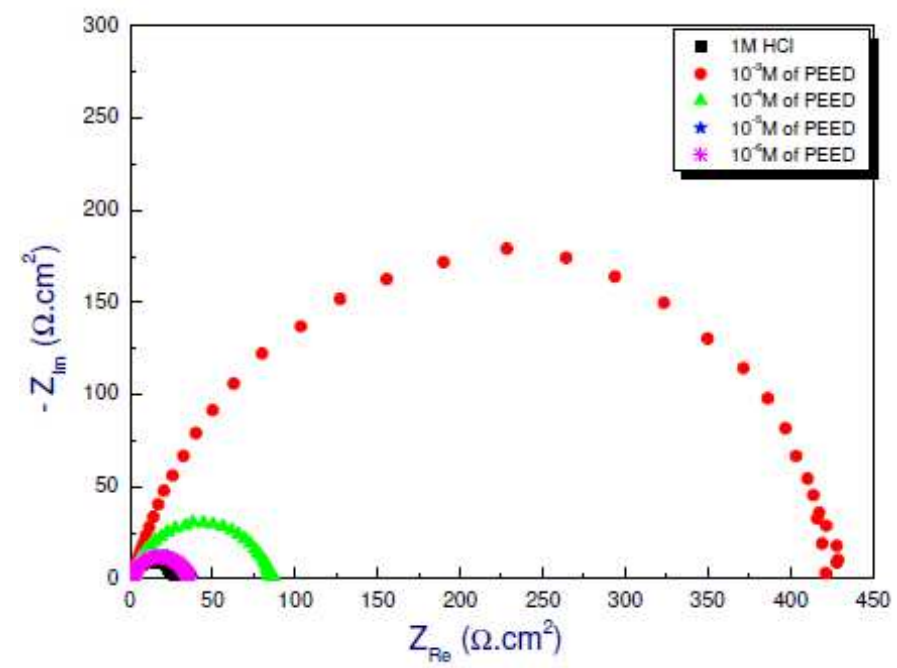

Figure 3. Nyquist diagrams for C-steel in a $1.0 \mathrm{M} \mathrm{HCl}$ solution containing various PEED concentrations, at $298 \mathrm{~K}$.

The impedance parameters derived from these plots are regrouped in Table 5.

Table 5. Electrochemical impedance parameters, and the corresponding inhibition efficiencies, for $\mathrm{C}$-steel in a 1.0 $\mathrm{M} \mathrm{HCl}$ solution, in PEED absence and presence.

\begin{tabular}{|c|c|c|c|c|c|c|}
\hline System & $\begin{array}{c}\mathbf{R}_{\mathrm{s}} \\
\left(\mathbf{\Omega . \mathbf { c m } ^ { 2 }}\right)\end{array}$ & $\begin{array}{c}\mathbf{C}_{\mathrm{dl}} \\
\left(\mu \mathrm{F} . \mathrm{cm}^{-2}\right)\end{array}$ & $\begin{array}{c}\mathbf{R}_{\mathrm{ct}} \\
\left(\mathbf{\Omega . c m ^ { 2 }}\right)\end{array}$ & $\begin{array}{l}f_{\max } \\
(\mathbf{H z})\end{array}$ & IE\% & $\Theta$ \\
\hline $1.0 \mathrm{M} \mathrm{HCl}$ solution & 1.9 & 162 & 28.0 & 50 & - & - \\
\hline $1.0 \mathrm{M} \mathrm{HCl}+1.0 \times 10^{-3} \mathrm{M}$ PEED & 3.3 & 43.5 & 425.8 & 8 & 93.4 & 0.934 \\
\hline $1.0 \mathrm{M} \mathrm{HCl}+1.0 \times 10^{-4} \mathrm{M}$ PEED & 1.5 & 113.0 & 84.5 & 20 & 66.8 & 0.668 \\
\hline $1.0 \mathrm{M} \mathrm{HCl}+1.0 \times 10^{-5} \mathrm{M}$ PEED & 1.2 & 121.0 & 35.9 & 40 & 22.0 & 0.220 \\
\hline $1.0 \mathrm{M} \mathrm{HCl}+1.0 \times 10^{-6} \mathrm{M}$ PEED & 0.9 & 126.0 & 35.6 & 40 & 21.3 & 0.213 \\
\hline
\end{tabular}

Double layer capacitance values $\left(\mathrm{C}_{\mathrm{dl}}\right)$ and charge-transfer resistance values $\left(\mathrm{R}_{\mathrm{ct}}\right)$ were obtained from the impedance measurements. $R_{c t}$ values were used to calculate the inhibition efficiency (IE\%), according to the following equation (6): 


$$
I E \%=\frac{\mathrm{R}_{\mathrm{ct}}-R_{c t}^{\prime}}{\mathrm{R}_{\mathrm{ct}}} * 100
$$

where $\mathrm{R}_{\mathrm{ct}}$ and $\mathrm{R}_{\mathrm{ct}}$ are the charge transfer resistance, in the inhibitor absence and presence, respectively.

The presence of a single capacitive loop in the impedance diagrams indicates the formation of a protective layer on the metal surface, leading to corrosion inhibition. This capacitive loop is generally attributed to the electronic charge transfer process [26].

From the results shown in Table 5, it can be seen that the charge transfer resistance $\left(R_{c t}\right)$ increases with higher inhibitor concentrations, while the double layer capacity $\left(\mathrm{C}_{\mathrm{dl}}\right)$ decreases. The decrease in $\mathrm{C}_{\mathrm{d} 1}$ values could be attributed to the inhibitory molecule adsorption (PEED) onto the metal surface [27], and to the replacement of the water molecules at the electrode interface by the organic inhibitor [28]. Therefore, the inhibitory efficiency increases with higher inhibitor concentrations, reaching a maximum value of $93.8 \%$, at $1.0 \times 10^{-3} \mathrm{M}$.

The Nyquist plots impedance was analyzed by fitting the experimental data to a simple equivalent circuit model presented in Fig. 4; it includes the solution resistance $\left(R_{s}\right)$ and the constant phase element $(C P E)$, which are placed in parallel to the charge transfer resistance $\left(R_{c t}\right)$.

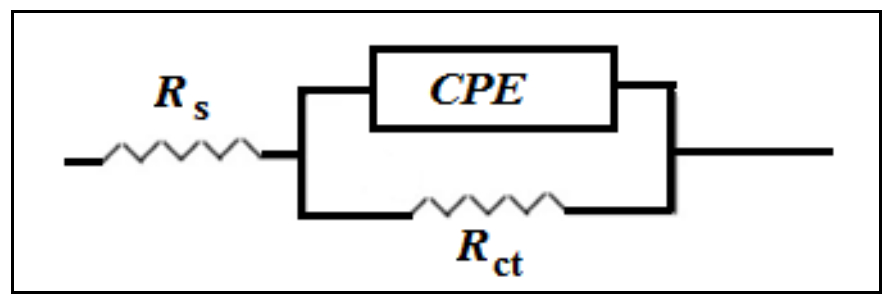

Figure 4. The equivalent circuit model used to fit the experimental EIS data.

\section{Effect of temperature}

\section{Polarization curves}

The effect of temperature on C-steel corrosion inhibition efficiency in a $1.0 \mathrm{M}$ $\mathrm{HCl}$ solution with optimal inhibitor concentration, at temperatures ranging from 298 to 328 K, was taken by potentiodynamic polarization measurements (Fig. 5).
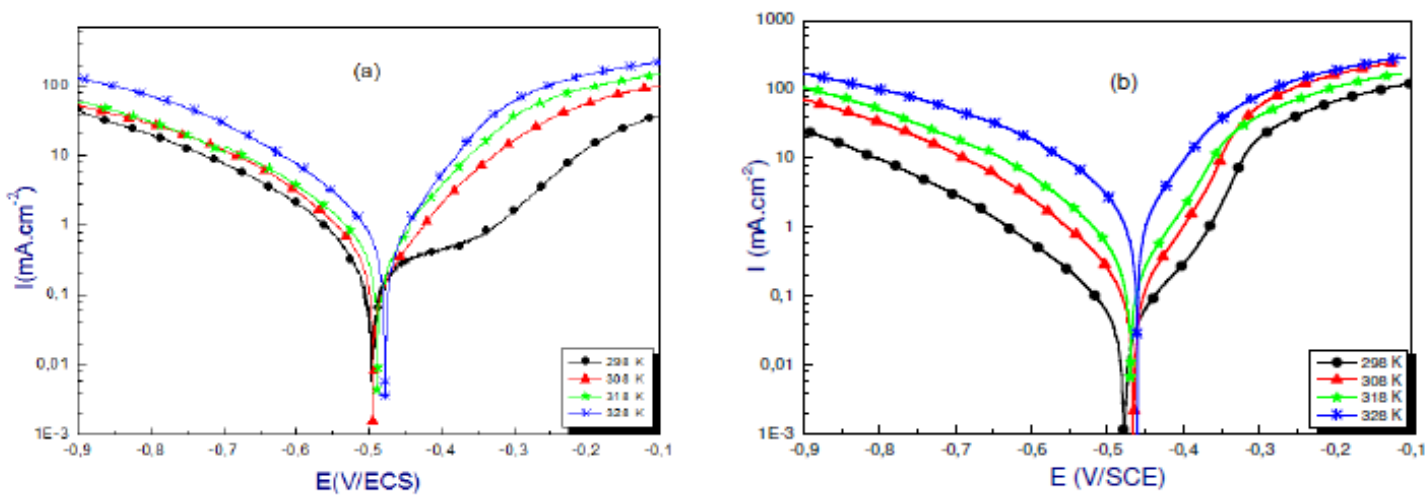

Figure 5. Polarization curves for C-steel at various temperatures in (a) a $1.0 \mathrm{M} \mathrm{HCl}$ solution and (b) optimal PEED concentration. 
The results obtained from the polarization curves are shown in Table 6 .

Table 6. Electrochemical polarization parameters and the corresponding inhibition efficiencies for $\mathrm{C}$-steel in a $1.0 \mathrm{M} \mathrm{HCl}$ solution, in the absence and presence of optimal PEED concentrations $\left(1.0 \times 10^{-3} \mathrm{M}\right)$.

\begin{tabular}{|c|c|c|c|c|c|c|}
\hline System & $\mathbf{T}(\mathbf{K})$ & $\begin{array}{c}E_{\text {corr }} \\
(m V \text { vs. SCE })\end{array}$ & $\begin{array}{c}\mathbf{I}_{\text {corr }} \\
\left(\mu \mathrm{A} . \mathrm{cm}^{-2}\right)\end{array}$ & $\begin{array}{c}\beta_{\mathbf{c}} \\
\left.(\mathbf{m V . d e c})^{-1}\right)\end{array}$ & 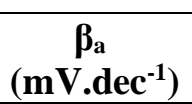 & $\begin{array}{l}\text { IE } \\
\%\end{array}$ \\
\hline \multirow{4}{*}{$\begin{array}{l}1.0 \mathrm{M} \mathrm{HCl} \\
\text { solution }\end{array}$} & 298 & -452 & 485 & -85 & 77 & - \\
\hline & 308 & -491 & 1200 & -184 & 112 & - \\
\hline & 318 & -475 & 1450 & -171 & 124 & - \\
\hline & 328 & -465 & 2200 & -161 & 118 & - \\
\hline \multirow{4}{*}{$\begin{array}{c}1.0 \mathrm{M} \mathrm{HCl} \\
+ \\
1.0 \times 10^{-3} \mathrm{M} \\
\text { PEED }\end{array}$} & 298 & -476 & 30 & -89 & 74 & 93.8 \\
\hline & 308 & -463 & 92 & -67 & 60 & 92.3 \\
\hline & 318 & -467 & 132 & -66 & 57 & 90.8 \\
\hline & 328 & -456 & 246 & 36 & 39 & 88.8 \\
\hline
\end{tabular}

Table 6 shows that the inhibition efficiency slightly increases with the decrease in temperature in the inhibitor presence, which indicates that higher temperatures may cause a slight inhibitor desorption from the C-steel surface.

\section{Kinetic parameters}

In order to get more details on the corrosion process, activation kinetic parameters, such as activation energies in free and inhibited acidic solutions, were calculated using Arrhenius equation:

$$
I_{\text {corr }}=A e^{\left(\frac{-E a}{R T}\right)}
$$

where $\mathrm{A}$ is Arrhenius factor, $\mathrm{E}_{\mathrm{a}}$ is the apparent activation corrosion energy $\left(\mathrm{KJ} \cdot \mathrm{mol}^{-1}\right), \mathrm{R}$ is the gas constant $\left(8.314 \mathrm{~J} \cdot \mathrm{mol}^{-1} \cdot \mathrm{K}^{-1}\right)$ and $\mathrm{T}$ is the absolute temperature $(\mathrm{K})$.

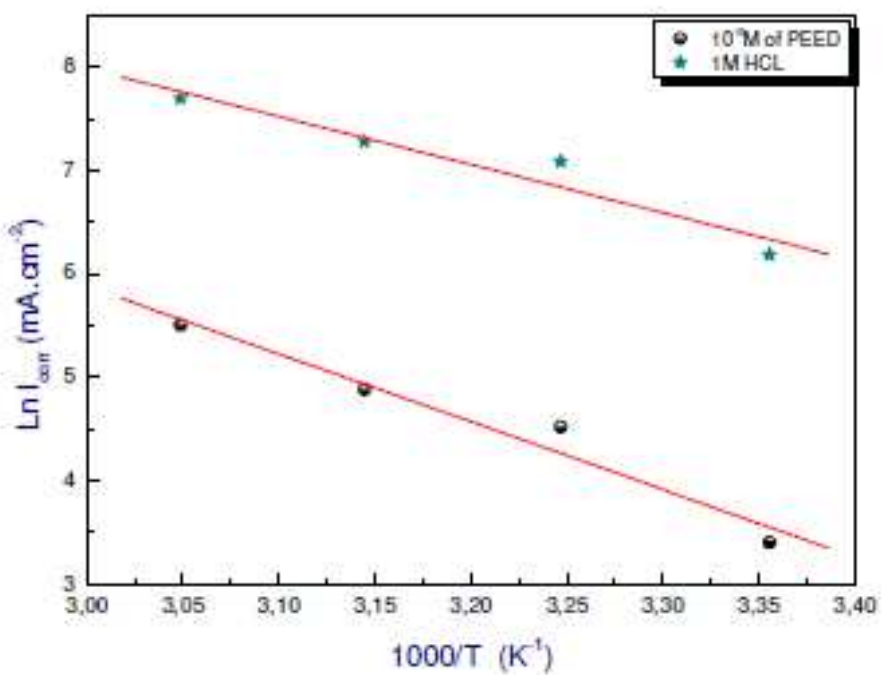

Figure 6. Arrhenius plots of $\mathrm{C}$-steel in a $1.0 \mathrm{M} \mathrm{HCl}$ solution, without and with $1.0 \times 10^{-3}$ $\mathrm{M}$ of PEED. 
The activation energy $\left(\mathrm{E}_{\mathrm{a}}\right)$ was calculated from the plots slope (Ln $\mathrm{I}_{\text {corr }}$ ) versus $(1000 / \mathrm{T})$ (Fig. 6), for C-steel in a $1.0 \mathrm{M} \mathrm{HCl}$ solution, with and without $1.0 \times 10^{-3}$ $\mathrm{M}$ of PEED, and is listed in Table 7.

The enthalpy and entropy of the corrosion process were determined from the effect of temperature, using the alternative Arrhenius formulation [29].

$$
\mathrm{I}_{\text {corr }}=\frac{\mathrm{RT}}{\mathrm{Nh}} \exp \left(\frac{\Delta \mathrm{S}^{*}}{\mathrm{R}}\right) \exp \left(-\frac{\Delta \mathrm{H}^{*}}{\mathrm{RT}}\right)
$$

where $\mathrm{N}$ is the Avogadro's number, $\mathrm{h}$ is the Plank's constant, $\mathrm{R}$ is the gas constant, and $\Delta \mathrm{S}^{*}$ and $\Delta \mathrm{H}^{*}$ are the entropy and enthalpy of activation, respectively.

Table 7. C-steel thermodynamic parameters in a $1.0 \mathrm{M} \mathrm{HCl}$ solution, in the absence and presence of $1.0 \times 10^{-3} \mathrm{M}$ of PEED.

\begin{tabular}{|c|c|c|c|}
\hline System & $\begin{array}{c}\mathbf{E}_{\mathbf{a}} \\
\left(\mathbf{k J . m o l}{ }^{-1}\right)\end{array}$ & $\begin{array}{c}\Delta \mathbf{H}^{*} \\
\left(\mathrm{KJ}^{*} \mathrm{~mol}^{-1}\right)\end{array}$ & $\begin{array}{c}\Delta \mathbf{S}^{*} \\
\left(\mathrm{~J} . \mathrm{mol}^{-1} \cdot \mathrm{K}^{-1}\right)\end{array}$ \\
\hline $1.0 \mathrm{M} \mathrm{HCl}$ solution & 38.6 & 36 & -71.3 \\
\hline $1.0 \mathrm{M} \mathrm{HCl}+1.0 \times 10^{-3} \mathrm{M}$ PEED & 54.46 & 51.86 & -41.3 \\
\hline
\end{tabular}

Fig. 7 shows the $\mathrm{Ln}\left(\mathrm{I}_{\text {corr }} / \mathrm{T}\right)$ plot of C-steel, as a function of $1000 / \mathrm{T}$ in a $1.0 \mathrm{M}$ $\mathrm{HCl}$ solution, in the absence and presence of $1.0 \times 10^{-3} \mathrm{M}$ of PEED at different temperatures.

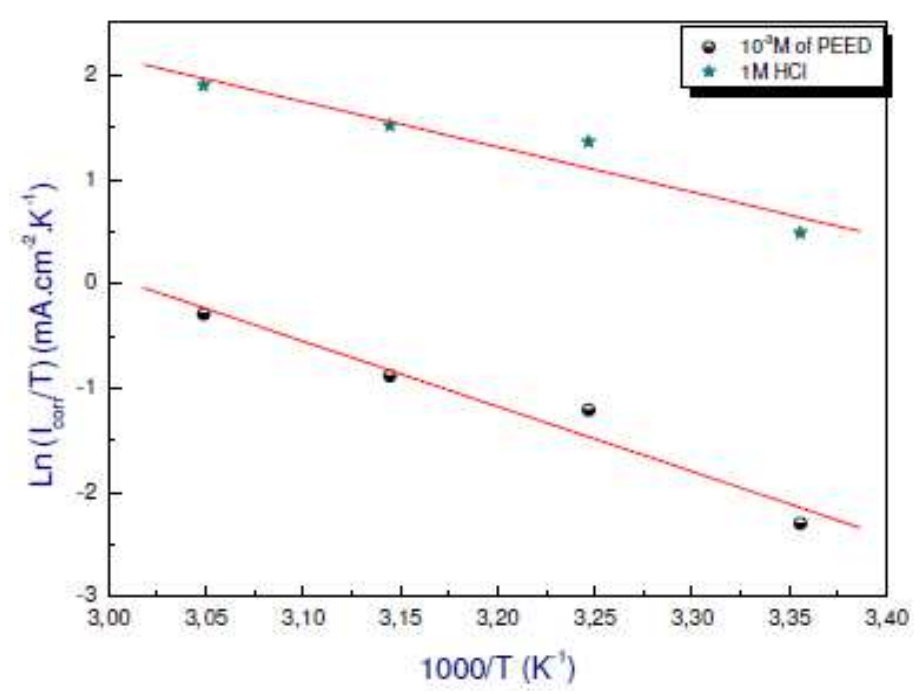

Figure 7. Variation of C-steel $\mathrm{Ln}\left(\mathrm{I}_{\text {corr }} / \mathrm{T}\right)$, in terms of $1000 / \mathrm{T}$ in a $1.0 \mathrm{M} \mathrm{HCl}$ solution, in the absence and presence of $1.0 \times 10^{-3} \mathrm{M}$ of PEED at different temperatures.

Table 7 clearly shows that the activation energy $\left(E_{a}\right)$ of the inhibited solution was higher than that of the uninhibited solution. Hence, it can be suggested that the inhibitor molecule (PEED) adsorption onto the C-steel surface in a $1.0 \mathrm{M} \mathrm{HCl}$ solution was carried out via physical adsorption [26].

The enthalpies positive sign reflects the endothermic nature of the $\mathrm{C}$-steel dissolution process. The entropy activation values $\left(\Delta \mathrm{S}^{*}\right)$ increase with the 
optimum PEED concentration, which implies that an increase in disordering is taking place on going from reactants to the activated complex [29].

\section{Adsorption isotherm}

Several adsorption isotherms were tested, and the Langmuir adsorption isotherm was found to be the best one to describe the adsorption behavior of the investigated inhibitor. The Langmuir isotherm is given by the following equations:

$$
\begin{aligned}
& \frac{\mathrm{C}_{\mathrm{inh}}}{\theta}=\frac{1}{\mathrm{~K}}+\mathrm{C}_{\mathrm{inh}} \\
& \Delta{G^{\circ}}^{\circ}{ }_{\text {ads }}=-R T \ln (55.5 \times K)
\end{aligned}
$$

where $\mathrm{C}$ is the inhibitor concentration, $\theta$ is the fraction of the $\mathrm{C}$-steel surface coverage, which is determined by $\mathrm{IE} \% / 100, \mathrm{~K}$ is the equilibrium constant for the adsorption/desorption process, $\Delta \mathrm{G}_{\text {ads }}$ is the standard free energy of the adsorption reaction, $\mathrm{R}$ is the universal gas constant, $\mathrm{T}$ is the thermodynamic temperature, and the value of 55.5 is the water concentration in the solution, in mol.L ${ }^{-1}$.

The plot of $\mathrm{C}_{\mathrm{inh}} / \theta$ as a function of $\mathrm{C}_{\mathrm{inh}}$ yielded a straight line, as shown in Fig. 8.

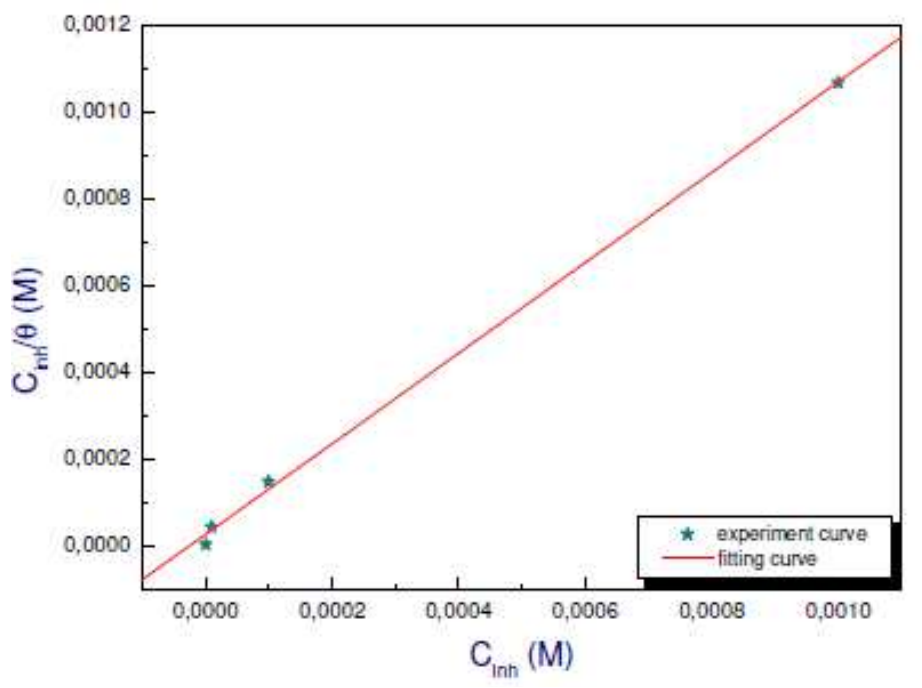

Figure 8. Plot of Langmuir adsorption isotherm of $1.0 \times 10^{-3} \mathrm{M}$ of PEED in a $1.0 \mathrm{M} \mathrm{HCl}$ solution onto the C-steel surface.

The linear regression coefficient $\left(\mathrm{R}^{2}\right)$ was almost equal to $1\left(\mathrm{R}^{2}=0.9999\right)$, and the slope approached unity, indicating that PEED adsorption onto the C-steel surface is well described by the Langmuir adsorption model. The calculated values of $\Delta \mathrm{G}_{\text {ads }}^{\circ}$ and $\mathrm{K}_{\mathrm{ads}}$ for PEED are regrouped in Table 8.

Table 8. Adsorption parameters of $1.0 \times 10^{-3} \mathrm{M}$ of PEED inhibitor for C-steel corrosion in a $1.0 \mathrm{M} \mathrm{HCl}$ solution, at $298 \mathrm{~K}$.

\begin{tabular}{|c|c|c|c|c|}
\hline Inhibitor & Slope & $\mathbf{R}^{\mathbf{2}}$ & $\mathbf{K}_{\text {ads }}\left(\mathbf{M}^{\mathbf{- 1}}\right)$ & $\Delta \boldsymbol{G}_{\boldsymbol{a d s} \mathbf{s}}^{\circ}\left(\mathbf{k J . m o l} \mathbf{H}^{\mathbf{1}}\right)$ \\
\hline PEED & 1.04 & 0.999 & $37.5 \times 10^{3}$ & -36 \\
\hline
\end{tabular}


When $\Delta \mathrm{G}_{\text {ads }}^{\mathbf{~}}$ values are around $-20 \mathrm{~kJ} \mathrm{~mol}^{-1}$, the interaction between the inhibitor molecule and the metal surface is associated with physisorption, while those of $40 \mathrm{~kJ}^{-\mathrm{mol}^{-1}}$ or higher involve a strong coordinate covalent bond, i.e., chemisorption [30-33]. In the present work, the $\Delta \mathrm{G}^{\mathrm{o}}$ ads value is equal to -36 $\mathrm{KJ} \mathrm{mol}^{-1}$, which means that the inhibitor molecule (PEED) adsorption onto the Csteel surface is chemisorption.

\section{Theoretical calculations}

\section{Molecular reactivity}

The calculated global descriptors responsible for the inhibition efficiency, obtained from theoretical calculations, such as the energy of the highest occupied molecular orbital ( $\left.\mathrm{E}_{\mathrm{HOMO}}\right)$, the energy of the lowest unoccupied molecular orbital (ELUMO), the energy gap $(\Delta \mathrm{E})$, and other descriptors obtained by $\mathrm{DMol}^{3}$ module at (GGA/HCTH/DNP+) level of theory in vacuum, are shown in Table 9.

Table 9. Quantum chemical parameters of PEED calculated by DMol3 module at (GGA/HCTH/DNP+) level in vacuum.

\begin{tabular}{|c|c|c|c|c|c|c|c|c|}
\hline Parameters & $\begin{array}{c}\text { Eномо } \\
(\mathbf{e V})\end{array}$ & $\begin{array}{c}\mathbf{E}_{\text {LUMo }} \\
(\mathbf{e V})\end{array}$ & $\begin{array}{c}\Delta \mathbf{E}_{\text {gap }} \\
(\mathbf{e V})\end{array}$ & $\begin{array}{c}\eta \\
(\mathbf{e V})\end{array}$ & $\begin{array}{c}\boldsymbol{\sigma} \\
\left(\mathbf{e V}^{-1}\right)\end{array}$ & $\begin{array}{c}\boldsymbol{\chi} \\
(\mathbf{e V})\end{array}$ & $\Delta \mathbf{N}$ & $\begin{array}{c}\mathbf{M} \\
(\mathbf{D})\end{array}$ \\
\hline Values & -5.975 & -0.428 & 5.547 & 2.773 & 0.360 & 3.201 & 0.684 & 4.322 \\
\hline
\end{tabular}

The optimization energy curves of the single inhibitor molecule, as well as the frontier molecular orbital distributions for PEED's neutral form, are shown in Figs. 9 and 10.

HOMO of PEED shows the electron density obtained from phenylethylidene rings, while LUMO predominantly came from the nitrogen atoms of ethanediamine; consequently, these are the favorite sites for the interaction with the metallic surface.

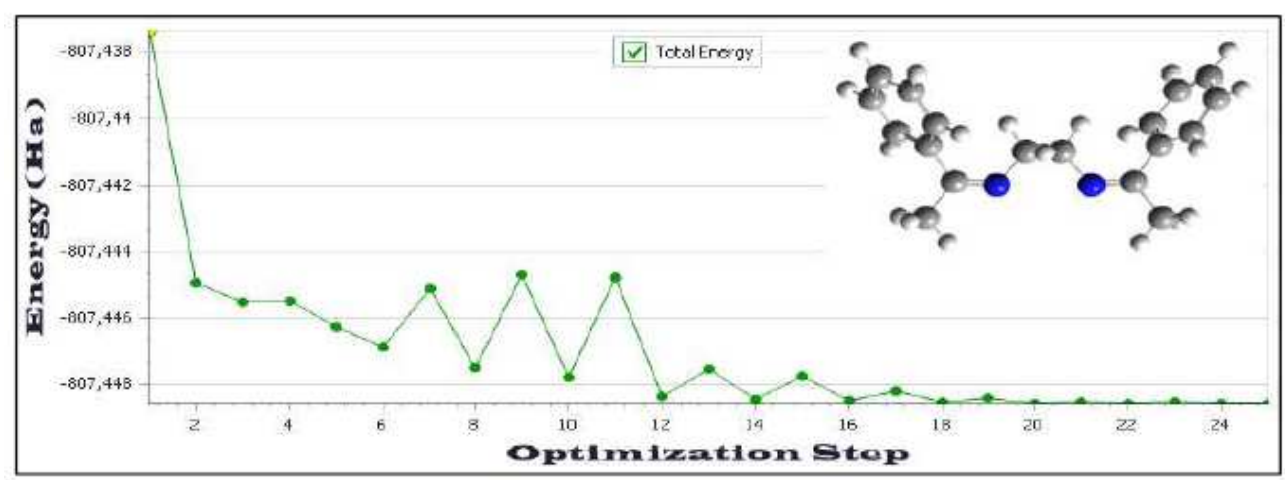

Figure 9. Geometry Optimization of PEED in an isolated form, calculated by DMol3 code.

Generally, the inhibitor adsorbs onto the metallic surface by a donor-acceptor interaction between the vacant d-orbital of the iron atoms and the $\pi$-electrons of the compound studied [34]. The energy gap value provides a measure for the stability of the formed complex on the metallic surface. As a result, there was 
good inhibition efficiency, due to the energy required for removing an electron from the lowest occupied orbital to the higher unoccupied orbital [35].

If the value of the charge transfer rate $(\Delta N)$ was $<3.6$, the inhibition efficiency increased with an increasing electron donor capacity on the steel / electrolyte interface [36], which was our case. The lower-dipole moment values $(\mu)$ will favor the inhibitor accumulation onto the metal surface layer; therefore, a higher inhibition efficiency will be reached [37].

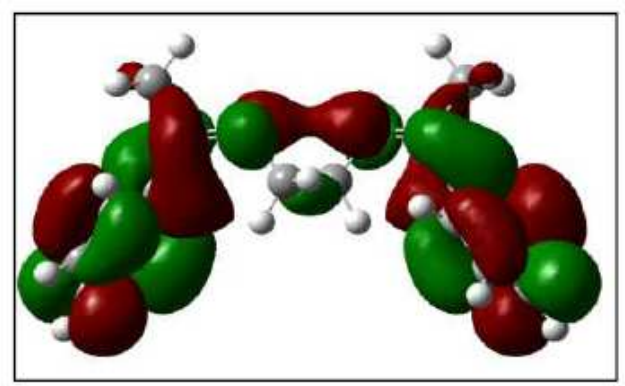

HOMO

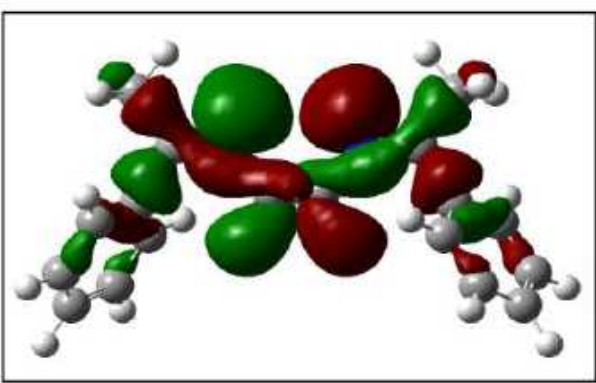

LUMO

Figure 10. HOMO and LUMO plots of PEED calculated by $\mathrm{DMol}^{3}$ module at (GGA/HCTH/DNP+) level in vacuum.

The calculated local Fukui functions and Mulliken atomic charges were used to analyze the local reactivity of the PEED inhibitor, and to reflect its local nucleophilicity and electrophilicity trend [37]. The calculated values of the local reactivity descriptors on the PEED's nitrogen atoms (N37 and N38) are given in Table 10.

Table 10. Calculated PEED's local Fukui functions and Mulliken atomic charges in gas phase.

\begin{tabular}{|c|c|c|}
\hline $\mathbf{f}^{-}$ & $\mathbf{f}^{+}$ & Mulliken atomic charges \\
\hline N37 (+0.046) & N37 (+0.072) & N37 (-0.415) \\
\hline N38 (+0.050) & N38 (+0.077) & N38 (-0.416) \\
\hline
\end{tabular}

It can be seen from Table 10 that the largest values of $\mathrm{f}^{-}$are located on the N37 and N38 heteroatoms, which indicates that these two heteroatoms prefer to form a chemical bond by electrons donation to the metallic surface. In its turn, the largest values of $\mathrm{f}^{+}$are located on the $\mathrm{N} 37$ and N38 heteroatoms, which further suggests that these are responsible for forming a back bond by the acceptance of electrons from the metal surface to the inhibitor (PEED), and vice versa.

\section{Monte Carlo simulation}

Monte Carlo (MC) simulations, using the adsorption locator module implemented in the Biovia Material Studio v8.0 software from Accelrys Inc. USA, were adopted to compute the interaction adsorption energy for the PEED inhibitor molecule / $\mathrm{Fe}(111)$ system in an hydrochloric acid medium. Fig. 11 shows the interaction energies fluctuant curves for the PEED inhibitor molecule $\left./ \mathrm{Fe}(111) / 110 \mathrm{H}_{2} \mathrm{O} / 2 \mathrm{HCl}\right)$ system. All calculations of total energy, vdWls energy, average total energy, electrostatic energy and intramolecular energy between 
PEED and the $\mathrm{Fe}(111)$ surface, in the adsorption process obtained by the adsorption locator module, are depicted in Fig. 11.

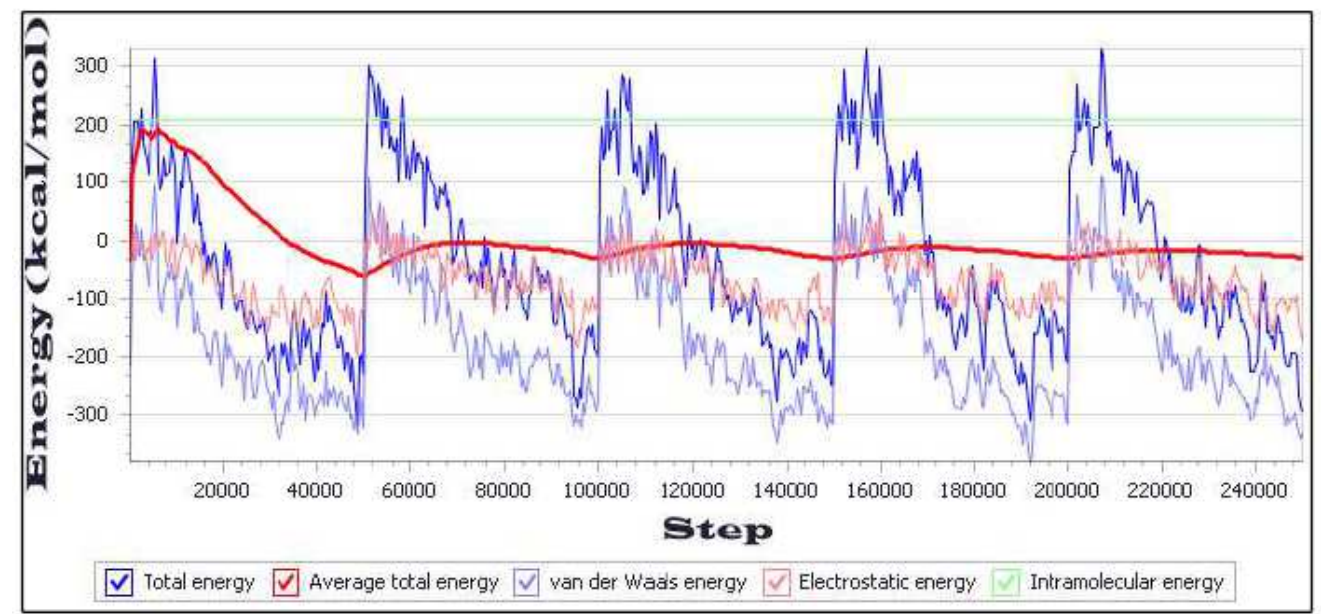

Figure 11. Interaction energies fluctuant curves of PEED on the $\mathrm{Fe}(111)$ surface in a hydrochloric acid solution.

The geometry optimization for the inhibitor molecule (PEED) was carried out using an iterative process, where atomic coordinates are adjusted until the total energy of the individual structure reaches the minimum energy, i.e., it corresponds to a local minimum in the potential energy surface. In this study, PEED has been placed on the iron (111) surface in a hydrochloric acid solution to find out the lowest adsorption energy sites, along with their suitable configuration obtained by the adsorption locator module, as shown in Fig. 12. Side and top views of the stable adsorption configurations, for one inhibitor molecule $(\mathrm{PEED}) / \mathrm{Fe}(111) / 110 \mathrm{H}_{2} \mathrm{O} / 2 \mathrm{HCl}$ system obtained by the adsorption

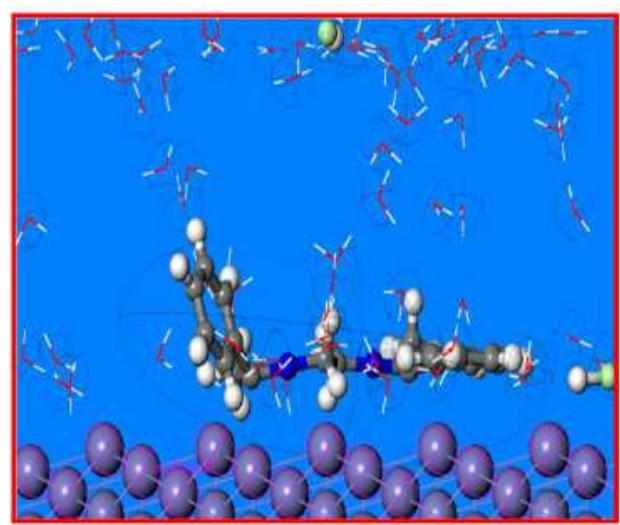

(a) Side view

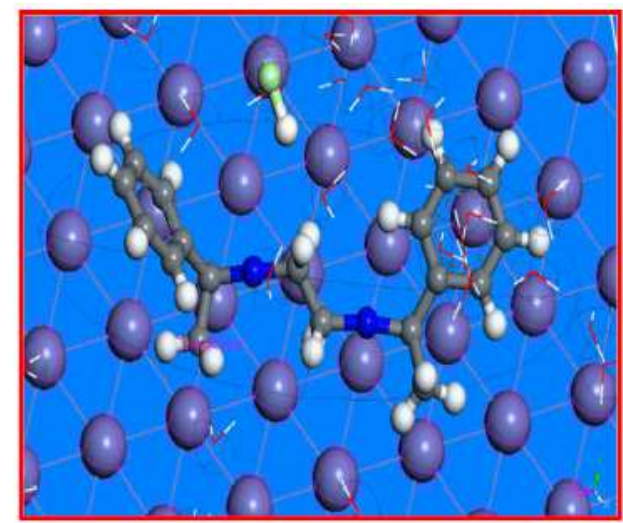

(b) Top view

Figure 12. Side and top views of the stable adsorption configurations for one inhibitor molecule $(\mathrm{PEED}) / \mathrm{Fe}(111) / 110 \mathrm{H}_{2} \mathrm{O} / 2 \mathrm{HCl}$ interface obtained by the adsorption locator module.

It can be noticed from Fig. 12 that the adsorption active sites of the PEED inhibitor, on the Fe (111) surface in an acidic medium, are the lone pair of nitrogen $(=\mathrm{N} 37-$ and $=\mathrm{N} 38-)$ atoms and $\pi-\pi$ electrons of the benzene ring. It was 
also observed that PEED adsorbed almost parallel onto the Fe (111) surface in the hydrochloric acid medium $\left(110 \mathrm{H}_{2} \mathrm{O} / 2 \mathrm{HCl}\right)$, in order to maximize the contact and surface coverage, ensuring a strong interaction between adsorbate and substrate. This is mainly due to the extension of a high inhibition effect experimentally observed $(\% \mathrm{IE}=93.8 \%)$. For PEED, the calculated dihedral angles around the phenyl-ethylidene ring were close to $0^{\circ}$ or $180^{\circ}$, indicating planarity of the phenyl-ethylidene ring.

The measured shortest bond distances (Fig. 12) between the active sites (=N37and $=\mathrm{N} 38-$ ) and the $\mathrm{Fe}(111)$ surface of the Fe-inhibitor (PEED) complex, in an hydrochloric acid solution at equilibrium, were as follows: $\left(\mathrm{d}_{\mathrm{Fe}-\mathrm{N} 37}: 3.452 \AA\right.$, and $\mathrm{d}_{\text {Fe-N38: }} 3.444 \AA$ ). The two distances of the bonds were above the value of $3.4 \AA$, which indicates that the interaction is of the vdWls type. The strong interaction of the system ensures that the chemical nature of the adsorption process is chemisorption, which was confirmed by the high energy value of R.A.E (in absolute values). This indicates that PEED inhibitor is an efficient inhibitor.

Several outputs and descriptors calculated by the adsorption locator module are presented in Table 11.

Table 11. Outputs and descriptors for the lowest adsorption configurations of PEED inhibitor molecule $/ \mathrm{Fe}(111) / 110 \mathrm{H}_{2} \mathrm{O} / 2 \mathrm{HCl}$ interface calculated by the adsorption locator module.

\begin{tabular}{|c|c|c|c|c|c|c|c|}
\hline System & $\begin{array}{l}\text { ETotal } \\
\mathbf{x 1 0}^{+3} \\
\text { kcal.mol }^{-1} \\
\end{array}$ & $\begin{array}{l}\text { EAds } \\
\mathbf{x 1 0}^{+3} \\
\text { kcal.mol }{ }^{-1} \\
\end{array}$ & $\begin{array}{l}\text { R.A.E } \\
10^{+3} \\
\text { kcal.mol }^{-1}\end{array}$ & $\begin{array}{l}D_{E} \\
\text { kcal.mol }^{-1}\end{array}$ & $\begin{array}{l}\mathrm{dE}_{\text {ads }} / \mathrm{dN}_{\mathrm{i}} \\
\text { Inh. } \\
\text { kcal.mol }^{-1}\end{array}$ & $\begin{array}{l}\mathrm{dE}_{\text {ads }} / \mathrm{dN}_{\mathrm{i}} \\
\text { water } \\
\text { kcal.mol }^{-1}\end{array}$ & $\begin{array}{l}\mathrm{dE}_{\text {ads }} / \mathrm{dN}_{\mathrm{i}} \\
\mathrm{HCl} \\
\text { kcal.mol }^{-1}\end{array}$ \\
\hline Substrate & 0.0000 & - & - & - & - & - & - \\
\hline PEED & +202.18 & - & - & - & - & - & - \\
\hline $\mathrm{H}_{2} \mathrm{O}$ & +0.0303 & - & - & - & - & - & - \\
\hline $\mathrm{HCl}$ & +1.6940 & - & - & - & - & - & - \\
\hline $\mathrm{Fe}(111)-1$ & -1.229 & -1.438 & -1.313 & -125.09 & -289.53 & -0.209 & -4.871 \\
\hline $\mathrm{Fe}(111)-2$ & -1.219 & -1.428 & -1.305 & -123.26 & -290.07 & 0.093 & -17.440 \\
\hline $\mathrm{Fe}(111)-3$ & -1.198 & -1.407 & -1.285 & -122.43 & -280.55 & -0.747 & -19.560 \\
\hline $\mathrm{Fe}(111)-4$ & -1.185 & -1.394 & -1.264 & -129.34 & -287.01 & -0.394 & -22.100 \\
\hline $\mathrm{Fe}(111)-5$ & -1.171 & -1.380 & -1.254 & -125.79 & -284.85 & -0.229 & -17.870 \\
\hline $\mathrm{Fe}(111)-6$ & -1.163 & -1.372 & -1.245 & -127.04 & -288.83 & -0.110 & -20.560 \\
\hline $\mathrm{Fe}(111)-7$ & -1.158 & -1.367 & -1.239 & -127.20 & -287.01 & -0.090 & -19.160 \\
\hline $\mathrm{Fe}(111)-8$ & -1.147 & -1.356 & -1.230 & -125.80 & -294.42 & -0.300 & -7.110 \\
\hline $\mathrm{Fe}(111)-9$ & -1.137 & -1.346 & -1.210 & -127.24 & -285.38 & -0.640 & -19.560 \\
\hline $\mathrm{Fe}(111)-10$ & -1.135 & -1.344 & -1.210 & -128.80 & -289.70 & -0.250 & -10.410 \\
\hline
\end{tabular}

The parameters include: total energy ( $\left.E_{\text {Total }}\right)$ for PEED inhibitor molecule $/ \mathrm{Fe}(111) / 110 \mathrm{H}_{2} \mathrm{O} / 2 \mathrm{HCl}$ system, which is defined as the sum of the energies of the adsorbate components, the rigid adsorption energy (R.A.E), and the deformation energy $\left(\mathrm{D}_{\mathrm{E}}\right)$. The substrate energy (Fe(111) surface) is taken as zero (Table 11). The adsorption energy ( $E_{A d s)}$ is related to the energy released (or required) when the relaxed adsorbate component was adsorbed onto the substrate. The adsorption energy is defined as the sum of the rigid adsorption energy and the deformation energy for the adsorbate component. The rigid adsorption energy is related to the energy released (or required) when the unrelaxed adsorbate component (before the geometry optimization step) was adsorbed onto the iron (111) surface. The deformation energy $\left(D_{E}\right)$ reports the energy released when the adsorbed component was relaxed on the substrate 
surface. Table 11 also shows $\left(\mathrm{dE}_{\mathrm{ad}} / \mathrm{dN}_{\mathrm{i}}\right)$, which reports the energies of PEED inhibitor, $\mathrm{H}_{2} \mathrm{O}$, and $\mathrm{HCl}$ configurations, where one adsorbate component has been removed. The values for the outputs and descriptors, calculated by the adsorption locator module for the Fe (111)/PEED/ system in an acidic solution, are displayed in Table 11.

Table 11 clearly shows that the adsorption energy value of the Fe-inhibiting (PEED) complex is negative $\left(-1.438 \times 10^{3} \mathrm{kcal}^{\mathrm{mol}} \mathrm{m}^{-1}\right)$, indicating that adsorption spontaneously occurs. The large negative value indicates that the Fe-(PEED) inhibitor complex is very stable, and that strong adsorption occurs in hydrochloric acid. The adsorption energy value of the PEED configuration was $-289.53 \mathrm{Kcal}^{\mathrm{mol}}{ }^{-1}$ at equilibrium, which is much higher than that of the $\mathrm{HCl}$

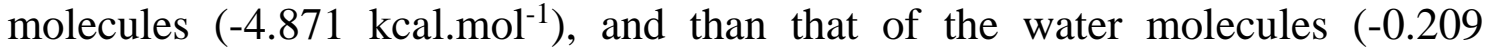
kcal.mol $\left.{ }^{-1}\right)$. This indicates the possibility of a progressive replacement of $\mathrm{H}_{2} \mathrm{O}$ and $\mathrm{HCl}$ molecules on the iron surface, leading to the formation of an inhibitor stable layer, which can protect the metallic surface against aqueous corrosion. These results indicate that the inhibiting molecule (PEED) has the strongest interaction on the iron surface in a hydrochloric acid solution, which corroborates very well the experimental results. The adsorption density of the inhibiting molecule (PEED), on the iron surface in a hydrochloric acidic solution, is presented in Fig. 13.

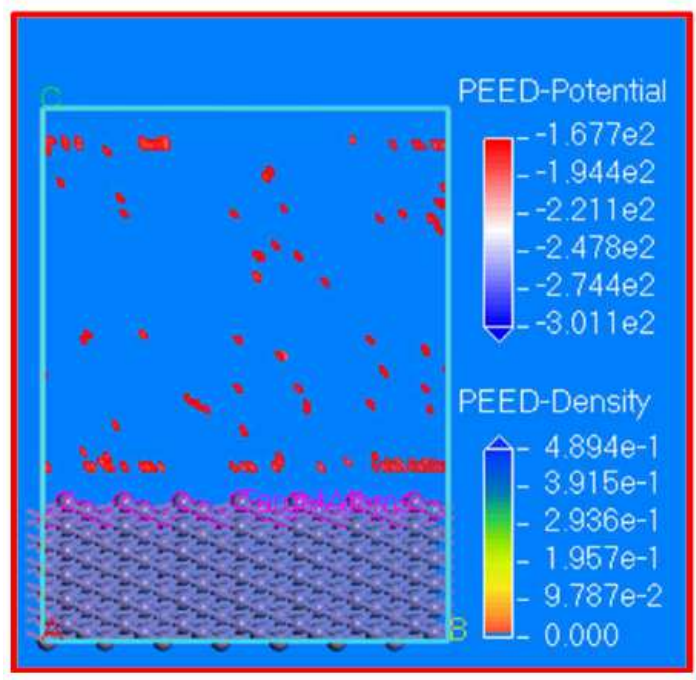

Figure 13. Adsorption density field of PEED-inhibitor molecule onto the $\mathrm{Fe}(111)$ substrate.

Fig. 13 shows a range from the minimum to the maximum value of the force field of PEED adsorption centers onto the Fe(111) surface in an acidic medium, and shows the minimum and average values of the entire field. The iso-surface colors change to reflect the minimum and maximum values associated with the field that has been mapped to the electron density using the electrostatic potential. Higher density of the dots means more likely adsorption actives sites onto the metal surface. In addition, the inhibitor has high binding energy to the Fe surface, as observed in Table 11. 


\section{Conclusions}

$>$ The studied PEED compound showed very good inhibition properties for Csteel corrosion in a $1.0 \mathrm{M} \mathrm{HCl}$ solution, reaching $93.8 \%$ at a concentration of $1.0 \times 10^{-3} \mathrm{M}$, and held at $298 \mathrm{~K}$.

$>$ The inhibition efficiency of the studied inhibitor increased with its higher concentrations.

$>$ The polarization curves study showed that PEED compound was classified as a mixed type inhibitor.

$>$ The electrochemical impedance study showed that the use of PEED significantly increases the charge transfer values, and decreases the double layer capacitance in a $1.0 \mathrm{M} \mathrm{HCl}$ solution, which indicates the formation of a protective film on the metallic surface.

$>$ PEED adsorption on the C-steel surface obeys the Langmuir adsorption isotherm.

$>$ Quantum chemical study revealed that PEED, in the neutral and isolated forms, had greater adsorption onto the iron surface. Molecular dynamic simulation also corroborated the experimental results.

\section{References}

1. El Kacimi Y, Touir R, Galai M, et al. Effect of silicon and phosphorus contents in steel on its corrosion inhibition in $5 \mathrm{M} \mathrm{HCl}$ solution in the presence of Cetyltrimethylammonium/KI. J Mater Environ Sci. 2016;7:371381.

2. Belghiti ME, Tighadouini S, Karzazi Y, et al. New hydrazine derivatives as corrosion inhibitors for mild steel protection in phosphoric acid medium. Part A: Experimental study. J Mater Environ Sci. 2016;7: 337-346.

3. Belghiti ME, Karzazi Y, Tighadouini S, et al. New Hydrazine Derivatives as Corrosion for mild steel in phosphoric acid medium. Part B: Theoretical investigation. J Mater Environ Sci. 2016;7:956-967.

4. Ben Hmamou D, Salghi R, Zarrouk A, et al. Alizarin red: an efficient inhibitor of C38 steel corrosion in hydrochloric acid. Int J Electrochem Sci. 2012;7:5716-5733.

5. Zarrouk A, Hammouti B, Al-Deyab SS, et al. Corrosion inhibition performance of 3,5-diamino-1,2,4-triazole for protection of copper in nitric acid solution. Int J Electrochem Sci. 2012;7:5997-6011.

6. Zarrouk A, Zarrok H, Salghi R, et al. A theoretical investigation on the corrosion inhibition of copper by quinoxaline derivatives in nitric acid solution. Int J Electrochem. 2012;7:6353-6364.

7. Adly OMI, Taha A, Fahmy SA. Synthesis, spectral characterization, molecular modeling and antimicrobial activity of new potentially N2O2 Schiff base complexes. J Molec Struct. 2013;1054-1055:239-250.

8. Materials Studio version 8.0.0.842, Accelrys Software Inc., San Diego: 2014. 
9. Becke AD. Density-functional thermochemistry. III. The role of exact exchange. J Chem Phys. 1993;98:5648-5652.

10. Eddy NO, Momoh-Yahaya H, Oguzie EE. Theoretical and experimental studies on the corrosion inhibition potentials of some purines for aluminum in 0.1 M HCl. J Adv Res. 2015;6:203-217.

11. Olasunkanmi LO, Kabanda MM, Ebenso EE. Quinoxaline derivatives as corrosion inhibitors for mild steel in hydrochloric acid medium: Electrochemical and quantum chemical studies. Physica E: LowDimensional Systems Nanostructures. 2016;76:109-126.

12. Ben Hmamou D, Salghi R, Zarrouk A, et al. Electrochemical and gravimetric evaluation of 7-methyl-2-phenylimidazo[1,2- $\alpha$ ]pyridine of carbon steel corrosion in phosphoric acid solution. Int $\mathrm{J}$ Electrochem Sci. 2013;8:1526-11545.

13. Shahabi S, Norouzi P, Ganjali MR. Theoretical and electrochemical study of carbon steel corrosion inhibition in the presence of two synthesized Schiff base inhibitors: application of Fast Fourier Transform continuous cyclic voltammetry to study the adsorption behavior. Int J Electrochem Sci. 2015;10:2646-2662.

14. Udhayakala P, Samuel AM, Rajendiran TV, et al. Theoretical assessment of corrosion inhibition performance of some pyridazine derivatives on mild steel. J Chem Pharmac Res. 2013;5:142-153.

15. Qachchachi FZ, Kandri Rodi Y, Elmsellem H, et al. Inhibitive Properties and Quantum Chemical Studies of (1-((1-benzyl-1H-1,2,3-triazol-4yl)methyl)indoline-2,3-dione on Mild Steel Corrosion in Acidic Medium. J Mater Environ Sci. 2016;7:2897-2907.

16. Chetouani A, Daoudi M, Hammouti B, et al. Inhibition of pure iron by new synthesized tripyrazole derivatives in $\mathrm{HCl}$ solutio. Corros Sci. 2006;48:2987-2997.

17. Pearson RG. Absolute electronegativity and hardness: application to inorganic chemistry. Inorg Chem. 1988;27:734-740.

18. Arslan T, Kandemirli F, Ebenso EE, et al. Quantum chemical studies on the corrosion inhibition of some sulphonamides on mild steel in acidic medium. Corros Sci. 2009;51:35-47.

19. Metropolis N, Rosenbluth AW, Rosenbluth MN, et al. Equation-of-state calculations by fast computing machines. J Chem Phys. 1953;21:10871092.

20. Frenkel D, Smit B. Understanding Molecular Simulation: From Algorithms to Applications. 2nd Edition. San Diego: Academic Press; 2002.

21. Sun H, Ren P, Fried JR. The COMPASS Forcefield: Parameterization and Validation for Phosphazenes. Comp Theor Polymer Sci. 1998;8:229-246.

22. Sourav $\mathrm{Kr} \mathrm{S}$, Abhiram $\mathrm{H}$, Naresh $\mathrm{CM}$, et al. A comparative density functional theory and molecular dynamics simulation studies of the corrosion inhibitory action of two novel N-heterocyclic organic compounds along with a few others over steel surface. J Mol Liq. 2016;215:486-495. 
23. Abdelahi MMM, Elmsellem H, Benchidmi M, et al. A DFT and Molecular Dynamics Study on Inhibitory Action of indazole Derivative on Corrosion of Mild Steel. J Mater Environ Sci. 2017;8:1860-1876.

24. Prabhu RA, Venkatesha TV, Praveen BM, et al. Inhibition Effect of Azadirachta indica, a Natural Product, on the Corrosion of Zinc in Hydrochloric Acid Solution. Trans Indian Inst Metals. 2014;67:675-679.

25. El Arrouji S, Ismaily Alaoui K, Zerrouki A, et al. The Influence of Some Pyrazole Derivatives on The Corrosion Behaviour of Mild Steel in $1 \mathrm{M} \mathrm{HCl}$ Solution. J Mater Environ Sci. 2016;7:299-309.

26. Ghazoui A, Benchat N, El-Hajjaji F, et al. The study of the effect of ethyl (6-methyl-3-oxopyridazin-2-yl) acetate on mild steel corrosion in $1 \mathrm{M} \mathrm{HCl}$. J Alloys Comp. 2017;693:510-517.

27. Bouoidina A, El-Hajjaji F, Chaouch $\mathrm{M}$, et al. Inhibition of mild steel corrosion using the extract of Foeniculum vulgare in acid medium._Der Pharma Chemica. 2016;8:149-157.

28. Fouda AS, Mostafa HA, El-Taiband F, et al. Synergistic influence of iodide ions on the inhibition of corrosion of C-steel in sulphuric acid by some aliphatic amines. Corros Sci. 2005;47:1988-2004.

29. Ech-chihbi E, Salim R, Oudda H, et al. The inhibition effect of imidazopyridine derivatives on C38 steel in hydrochloric acid solution. Der Pharma Chemica. 2016;8:200-213.

30. Hussin MH, Kassim MJ. The corrosion inhibition and adsorption behavior of Uncaria gambir extract on mild steel in $1 \mathrm{M} \mathrm{HCl} \mathrm{M}$. Mater Chem Phys. 2011;125:461-468.

31. El Ouasif L, Merimi I, Zarrok H, et al. Synthesis and inhibition study of carbon steel corrosion in hydrochloric acid of a new surfactant derived from 2-mercaptobenzimidazole. J Mater Environ Sci. 2016;7:2718-2730.

32. John S, Joseph A. Electro analytical, surface morphological and theoretical studies on the corrosion inhibition behavior of different 1,2,4-triazole precursors on mild steel in $1 \mathrm{M}$ hydrochloric acid. Mater Chem Phys. 2012;133:1083-1091.

33. Niouri W, Zerga B, Sfaira M, et al. Electrochemical and chemical studies of some benzodiazepine molecules as corrosion inhibitors for mild steel in 1 M HCl. Int J Electrochem Sci. 2014;9:8283-8298.

34. Belghiti ME, Karzazi Y, Dafali A, et al. Anti-corrosive properties of 4amino-3,5-bis(disubstituted)-1,2,4-triazole derivatives on mild steel corrosion in $2 \mathrm{M} \mathrm{H} 3 \mathrm{PO} 4$ solution: Experimental and theoretical studies. J Mol Liq. 2016;216:874-886.

35. Saha SKr, Ghosh P, Chowdhury AR, et al. Corrosion Control of Chrome Steel Ball in Nitric Acid Medium Using Schiff Base Ligand and Corresponding Metal Complexes: A Combined Experimental and Theoretical Study. Can Chem Trans. 2014;2:381-402.

36. Lgaz H, Salghi R, Larouj M, et al. Experimental, Theoretical and Monte Carlo simulation of quinoline derivative as effective corrosion inhibitor for mild steel in $1 \mathrm{M} \mathrm{HCl}$. J Mater Environ Sci. 2016;7:4471-4488. 
37. Belghiti ME, Karzazi Y, Dafali A, et al. Experimental, quantum chemical and Monte Carlo simulation studies of 3,5-disubstituted-4-amino-1,2,4triazoles as corrosion inhibitors on mild steel in acidic medium. J Mol Liq. 2016;218:281-293. 